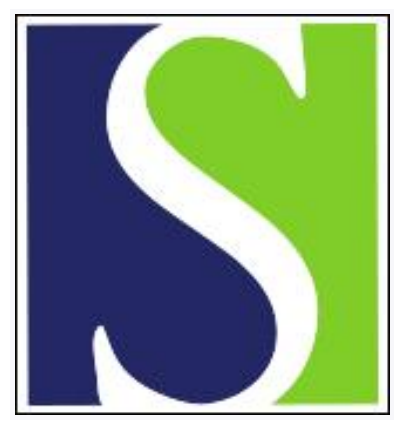

Scand J Work Environ Health 1992;18(6):368-375

https://doi.org/10.5271/sjweh.1560

Issue date: 01 Dec 1992

Role of psychosocial risk factors in work-related low-back pain. by Feyer AM, Williamson A, Mandryk J, de Silva I, Healy S

Affiliation: National Institute of Occupational Health and Safety, Sydney, Australia.

This article in PubMed: www.ncbi.nlm.nih.gov/pubmed/1485162

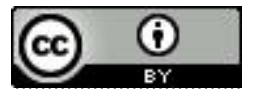




\title{
Role of psychosocial risk factors in work-related low-back pain
}

\author{
by Anne-Marie Feyer, PhD, ${ }^{1,2}$ Ann Williamson, PhD, ${ }^{1,2}$ John Mandryk, PhD, ${ }^{1,2}$ \\ Indira de Silva, MB, ${ }^{1}$ Sandy Healy, BA $^{1}$
}

\begin{abstract}
FEYER A-M, WILLIAMSON A, MANDRYK J, de SILVA I, HEALY S. Role of psychosocial risk factors in work-related low-back pain. Scand J Work Environ Health 1992;18:368-75. The experience of low-back pain and its psychosocial associates were directly compared among sufferers drawn from three populations, a blue-collar working group, a white-collar working group, and a patient group. Sufferers drawn from the patient population revealed the expected psychological disturbance. There was no evidence of such involvement for sufferers still at work. Disability resulting from low-back pain was positively linearly related to severity of pain for sufferers drawn from working groups, irrespective of psychological disturbance. For patients, on the other hand, the presence of psychological disturbance modified the relationship between severity and disability such that no simple linear relationship existed between the two variables. Work dissatisfaction was not found to be related to the presence of, and did not account for disability resulting from, low-back pain in working subjects.
\end{abstract}

Key terms: disability, etiology, premorbid risk indicators, prospective study, severity of pain, time off work, work dissatisfaction.

The association of nonphysical factors with low-back pain has been one of the more robust findings in the literature reporting factors associated with low-back pain. Two factors, psychological state and aspects of work satisfaction, have been the main focus of research. Low-back pain has been consistently associated with neurotic signs such as depression, anxiety, and heightened somatic awareness in low-back pain sufferers drawn from patient populations $(1-5)$. While several studies have suggested similar associations between psychological factors and low-back pain in nonpatient populations, the findings have not been consistent $(6-10)$.

Aspects of the work environment and work satisfaction have also been found to be associated with lowback pain in industrial and general population studies. Several studies have reported that sufferers of low-back pain and back injury claimants are more likely to be dissatisfied with their jobs (11-13), attract poor appraisal from supervisors (14), and be more likely to experience a poor psychosocial work environment $(15$, 16), but contradictory findings have also been reported $(17,18)$.

A problem for the interpretation of these findings has been the absence of prospective investigations of the involvement of nonphysical factors in the occurrence of back pain in working populations. This lack

1 National Institute of Occupational Health and Safety, Sydney, Australia.

2 The University of Sydney, Sydney, Australia.

Reprint requests to: Dr A-M. Feyer, National Institute of Occupational Health and Safety, GPO Box 58, Sydney NSW 2001, Australia. has made the determination of cause-effect relationships difficult. Recently, Bigos and his colleagues (19) conducted a prospective study of the role of nonphysical factors in the response to back pain at work, namely, whether or not an individual will file a back injury report. They found that aspects of psychological response, measured by the Minnesota Multiphasic Personality Inventory (MMPI), and work dissatisfaction predicted the incidence of back injury claims in a large heterogeneous group working in a low-risk setting. However, the MMPI scores for these working subjects did not reflect the pattern of neurotic symptoms typically reported for chronic patients attending pain clinics, or even score elevations outside the normal range. Furthermore, the strength of prediction was considerably greater when both psychosocial risk factors and a prior history of treated back injury were present.

The etiologic role of nonphysical factors in the development of occupational low-back pain remains largely unresolved. In particular, it is unclear whether psychosocial factors act as determinants or associates of pain sensation or pain experience and whether this experience is differentially affected by being, or having been, a patient with established low-back pain.

The aim of the present study was to compare the psychosocial associates of low-back pain among sufferers who remain at work and those who do not. Furthermore; within the group who remain at work, the study also sought to examine the relationship between work satisfaction and the experience of low-back pain. Since several studies have suggested that exposure to monotonous work may be related to low-back pain $(15,16)$, both a blue- and a white-collar group was included in the study. 


\section{Subjects and methods}

\section{Methods}

A self-report questionnaire was designed to gather information on low-back pain and possible risk indicators of low-back pain. The questionnaire consisted of three instruments.

Presence and degree of disability. The first instrument in the questionnaire was designed to obtain information about the presence of low-back pain, its onset and progress, the anatomical site affected, and the professional help sought. The subjects were also asked about the worst episode of low-back pain they had experienced during the last 12 months. The severity of this episode was described by the subject on a $100-\mathrm{mm}$ visual analogue scale ranging from "not severe at all" to "very severe." The disability caused by low-back pain during the worst episode was evaluated by twoand three-item questions, covering a range of activities such as daily living, social life, sport, other recreation, and work. In addition, the subjects were asked if they took time off work during the worst episode of low-back pain, and, if so, the number of days taken.

Psychological components of ill health. The psychological components of ill health were measured with the 28-item General Health Questionnaire (GHQ) (20). The GHQ assesses specific dimensions of the psychological state of participants. It is a normed and extensively used scale which provides measures of somatic symptoms, anxiety and insomnia, social dysfunction, and severe depression.

Perceptions of the work environment. Perceptions of the work environment were evaluated with an adaptation of the Work Environment Scale (21). This scale consists of 90 items divided into 10 subscales which describe individuals' perceptions of different aspects of their work environment. The 10 subscales are involvement, peer cohesion, supervisor support, autonomy, task orientation, work pressure, clarity, control, innovation, and physical comfort. For each item the subjects select one of two options, true or false. This instrument was adapted so that, for each item, the subjects were also asked to describe how they would like their work environment to be. The discrepancy between the actual and preferred work environment scores provided a measure of dissatisfaction with the actual work environment.

\section{Subjects}

A high-risk white-collar group, a high-risk blue-collar group and a chronic low-back pain patient group were chosen for study. The white-collar group consisted of registered nursing staff at a large teaching hospital in Sydney. All of the members of the ward staff present when the study team member visited each ward were approached to participate in the study. There were no refusals. A total of 257 members of staff, representing all sectors of the hospital, volunteered to participate. The aim was to recruit a reasonably representative sample of nurses from all units of the hospital, since practical constraints made it too difficult to obtain a truly random sample. One hundred and seventythree questionnaires were returned, of which 164 (64\%) were complete and used in the analysis.

For the blue-collar working group, 256 postal workers, consisting of both postal delivery officers and mail sorting officers, volunteered to participate. Employees in 10 metropolitan Sydney post offices and seven mail centers were approached, the aim once again being to recruit a representative sample rather than a truly random one. Again, all members of the staff present when the study team member called at the workplaces were approached to participate in the study; no refusals were encountered. Of the 85 postal delivery officers who volunteered, $57(67 \%)$ returned completed questionnaires. Of the 171 mail sorting officers who volunteered, $59(36 \%)$ returned completed questionnaires. A total of $116(45 \%)$ of the postal workers returned a completed questionnaire.

The third group of subjects consisted of low-back pain patients attending a pain management clinic in Sydney. All of the patients present when the study team member visited the clinic were approached to participate in the study. Again, there were no refusals. Fiftyone patients agreed to participate in the study. The patients comprised both new cases attending the clinic for the first time and cases who had been attending the clinic during the past one to two years. They were asked to complete the questionnaire while they waited to see the physician, or immediately afterwards. Fortyeight questionnaires were returned, $45(88 \%)$ of which were complete and used in the analysis. At the time the questionnaire was completed, less than half $(42 \%)$ of the patients were still at work in some capacity.

\section{Analysis}

Statistical analysis was carried out with the SAS PC (statistical analysis system for the personal computer) package (22). Comparisons were made using Student's t-test, analysis of variance, and the chi-square test for proportions. Multiple linear regression analysis and multiple logistic regression analysis were used to test for predictions of time off work and disability caused by low-back pain.

Comparison of the pattern of responses obtained from the two subgroups of the postal worker group revealed that there were no differences between mail sorting officers and mail delivery officers on the variables of interest. They were, therefore, analyzed as a single group. 


\section{Results}

The majority $(93 \%)$ of the nurses were female while the majority $(72 \%)$ of postal workers were male. The two genders were equally represented among the chronic low-back pain patients. The two working populations tended to be young, the majority $(78 \%$ of the nurses and $70 \%$ of the postal workers) being below 40 years of age. The patients were a much older group with only $29 \%$ below 40 years of age.

Table 1. Major sites of low-back pain among the low-back pain cases. ${ }^{a}$

\begin{tabular}{lccc}
\hline Site & $\begin{array}{c}\text { Nurses } \\
(\%)\end{array}$ & $\begin{array}{c}\text { Postal } \\
\text { workers } \\
(\%)\end{array}$ & $\begin{array}{c}\text { Low-back pain } \\
\text { patients } \\
(\%)\end{array}$ \\
\hline $\begin{array}{l}\text { Fourth and fifth } \\
\text { lumbar vertebrae } \\
\text { and lumbosacral }\end{array}$ & & & \\
junction & 84 & 68 & 73 \\
Right gluteal region & 67 & 59 & 76 \\
Sacral and coccygeal & 67 & 70 & 87 \\
regions & 60 & 57 & 73 \\
\hline
\end{tabular}

a Percentages do not add up to $100 \%$ because the subjects reported multiple sites.
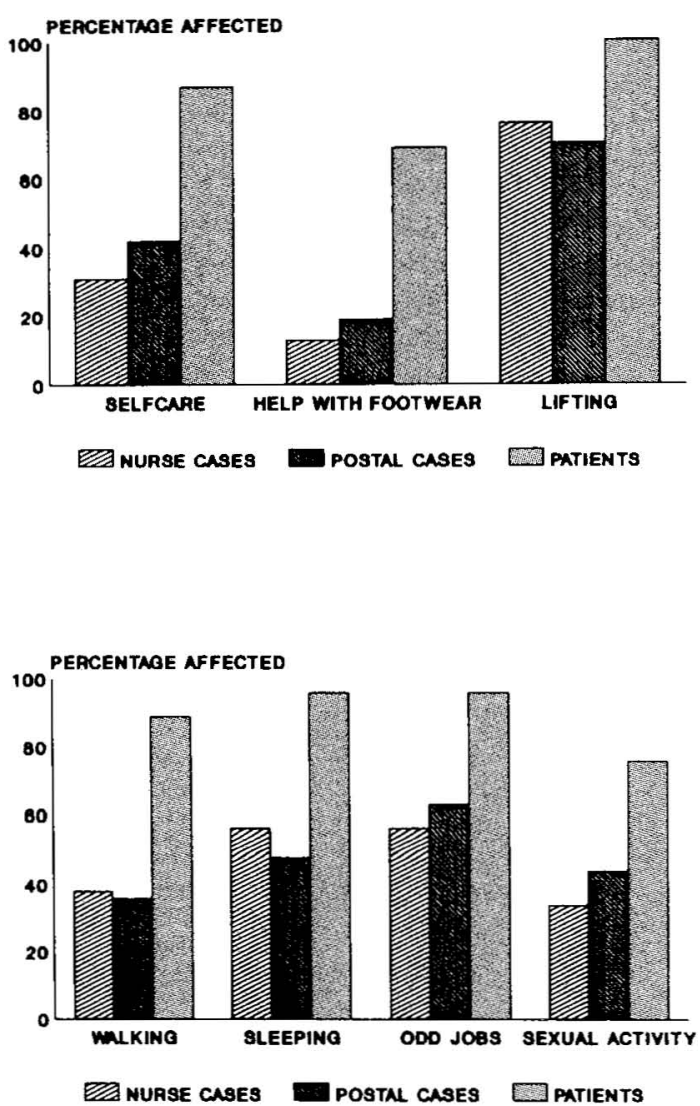

\section{Low-back pain}

The lifetime prevalence of low-back pain (those who had ever had low-back pain) was $77 \%$ among the nurses and $73 \%$ among the postal workers. The point prevalence of low-back pain (those with current lowback pain) was $26 \%$ for both populations, while the one-year period prevalence (those who had had lowback pain within the last year) was $67 \%$ for the nurses and $56 \%$ for the postal workers. The latter group of

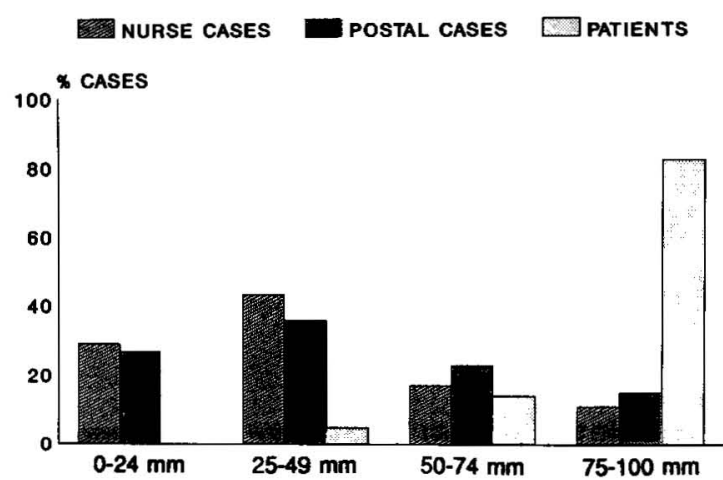

Figure 1. Severity of low-back pain as marked on the visual analogue scale, presented in quartiles.
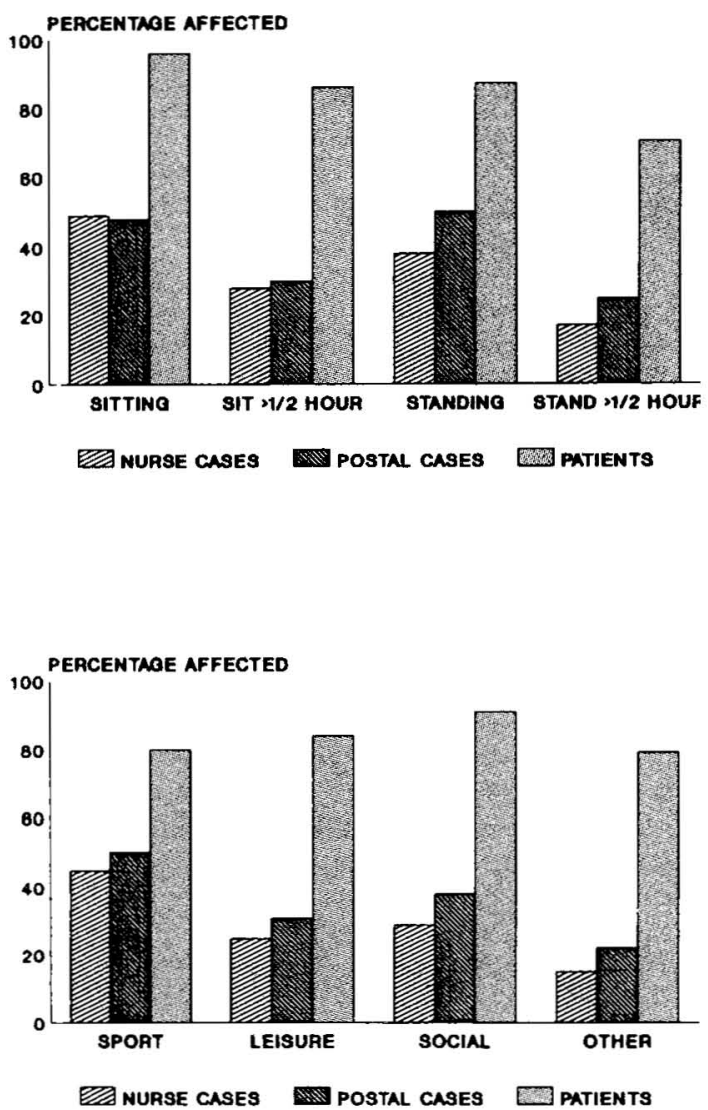

Figure 2. Disability caused by low-back pain, showing the proportion of cases affected in each of the activities by group. 
participants (those who had had low-back pain within the last year) provided information about the severity of, and disability experienced from, low-back pain, and these participants are referred to as low-back pain cases. The participants who had never had low-back pain or had it more than one year ago are referred to as noncases.

Back pain was usually of more recent onset (within the last year) for the cases among the nurses and postal workers than it was for the low-back pain patients. Only $7 \%$ of the patients reported onset within the last year compared with $21 \%$ of the cases among the nurses and $30 \%$ of the cases among the postal workers. Twenty-eight percent of the cases among the nurses and $48 \%$ of the cases among the postal workers sought professional help for low-back pain. As already mentioned, all of the low-back pain patients were recruited from a pain management clinic and hence were seeking professional help at the time of the study.

The low-back pain cases were asked to indicate where the pain was located on a diagram of the lower back. See Biering-Sorenson (23) for a full description. Table 1 summarizes the results for the major sites. Interestingly, similar sites were reported by both the chronic low-back pain patients and the low-back pain cases still at work.

The length of the worst episode of low-back pain in the last 12 months was shorter for the nurses and postal workers (less than one week) than it was for the low-back pain patients (more than one week, with more than one month for $36 \%$ of the subjects). The degree of pain experienced during the worst episode is displayed in figure 1 . While the low-back pain cases among the nurses and postal workers registered low levels of pain in general, a substantial proportion of these at-work populations registered pain in the higher ranges. For the most part, the patients reported their pain levels as being in these higher ranges (figure 1). For ease of comparison, these originally continuous data have been grouped into quartiles in figure 1 .

The subjects indicated how debilitating their pain was with respect to activities of daily living. Figure 2 shows the percentage affected (either performed the activity with additional pain or could not perform the activity because of pain) on each activity for the three study populations. Although more than $90 \%$ of the patients reported being affected in these activities, a substantially high proportion of the two working populations (more than 50\%) was also affected.

Disability was summarized by the mean number of activities affected due to low-back pain and also the mean number of activities which could not be performed because of pain (table 2). Not surprisingly, in terms of this measure, the chronic low-back pain patient group was significantly more disabled than the cases in the two working populations.

Working low-back pain cases also indicated the degree to which pain during the worst episode had affected work activities. In each of the working groups, approximately $35 \%$ of the cases reported having had to change their work duties during this episode of pain. More than twice as many postal worker cases $(36 \%)$ as nurse cases $(13 \%)$ reported having had to take time off from work during the worst episode of low-back pain during the last 12 months. Approximately half of the patients were still working during the worst episode experienced in the previous 12 months. Of these, the vast majority $(96 \%)$ took time off work because of pain.

\section{Work satisfaction}

The subjects' perceptions of their actual work environment were compared with their perceptions of how they would like their work environment to be. The difference between the real and ideal responses provides a measure of dissatisfaction with the actual work environment (only absolute differences were counted (ie, true in real scale and false in ideal scale or vice versa). High scores imply a greater dissatisfaction than low scores. Overall, figure 3 shows that the postal workers were significantly more dissatisfied with their work environment than were the nurses $(F=9.9359$, $\mathbf{P}<0.0001)$. However, the low-back pain cases among

Table 2. Disability caused by low-back pain.

\begin{tabular}{|c|c|c|c|c|}
\hline \multirow[t]{2}{*}{ Group } & \multicolumn{2}{|c|}{$\begin{array}{l}\text { Number of } \\
\text { activities } \\
\text { performed with } \\
\text { additional pain }\end{array}$} & \multicolumn{2}{|c|}{$\begin{array}{c}\text { Number of } \\
\text { activities } \\
\text { not performed } \\
\text { because of pain }\end{array}$} \\
\hline & Mean & SD & Mean & SD \\
\hline $\begin{array}{l}\text { Nurse cases } \\
\text { Postal cases } \\
\text { Patients }\end{array}$ & $\begin{array}{r}5.36 \\
5.98 \\
12.73\end{array}$ & $\begin{array}{l}4.01 \\
4.51 \\
1.92\end{array}$ & $\begin{array}{l}1.43 \\
1.48 \\
3.51\end{array}$ & $\begin{array}{l}1.09 \\
1.28 \\
1.70\end{array}$ \\
\hline
\end{tabular}

a $P<0.0001$ for analysis of variance between the three groups.

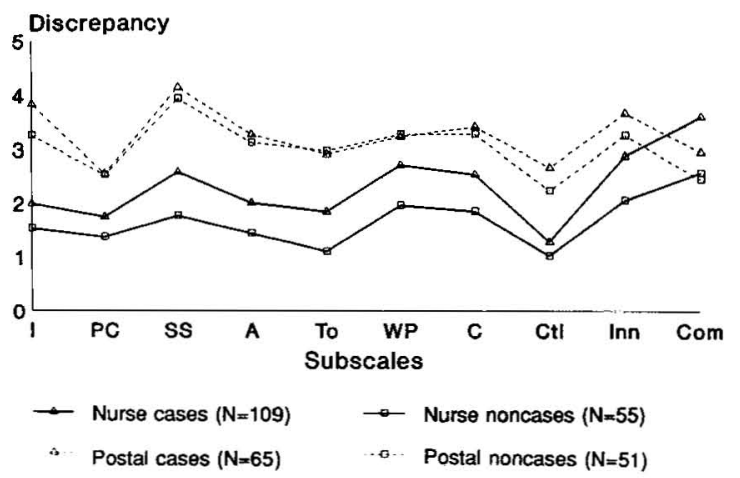

Figure 3. Discrepancy between real and ideal perceptions of the work environment for each of the groups on each of the subscales of the Work Environment Scale (21). High scores on the discrepancy scale imply more dissatisfaction with the work environment. ( 1 = involvement, $\mathbf{P C}=$ peer cohesion, $\mathbf{S S}=$ supervisor support, $\mathrm{A}=$ autonomy, $\mathrm{To}=$ task orientation, $\mathrm{WP}=$ work pressure, $\mathrm{C}=$ clarity, $\mathrm{CtI}=$ control, Inn = innovation, Com = physical comfort) 
the postal workers did not differ significantly from the postal noncases in this respect. There was a tendency for the nurse cases to express a consistently greater degree of dissatisfaction with the actual work environment than that expressed by the nurse noncases. However, for only one subscale, task orientation (To), was there a significant difference $(\mathrm{t}=3.02, \mathrm{P}<0.003)$.

\section{Psychological state}

The mean GHQ score was 2.67 for the working noncases, 3.79 for the working cases, and 12.4 for the patients. For the statistical analysis, the scores were ex-

Table 3. General health questionnaire (GHQ) scores.

\begin{tabular}{|c|c|c|c|c|c|}
\hline \multirow[b]{2}{*}{ Score } & \multicolumn{2}{|c|}{ Nurses } & \multicolumn{2}{|c|}{ Postal workers } & \multirow{2}{*}{$\begin{array}{c}\begin{array}{c}\text { Low-back pain } \\
\text { patients }\end{array} \\
(\%)\end{array}$} \\
\hline & $\begin{array}{c}\text { Cases } \\
(\%)\end{array}$ & $\begin{array}{c}\text { Non- } \\
\text { cases } \\
(\%)\end{array}$ & $\begin{array}{c}\text { Cases } \\
(\%)\end{array}$ & $\begin{array}{c}\text { Non- } \\
\text { cases } \\
(\%)\end{array}$ & \\
\hline $\begin{array}{l}\mathrm{GHQ} \leq 5 \\
\mathrm{GHQ}>5\end{array}$ & $\begin{array}{l}77 \\
23\end{array}$ & $\begin{array}{l}87 \\
13\end{array}$ & $\begin{array}{l}74 \\
26\end{array}$ & $\begin{array}{l}84 \\
16\end{array}$ & $\begin{array}{l}20 \\
80\end{array}$ \\
\hline
\end{tabular}

Table 4. Multiple logistic regression of time off work.

\begin{tabular}{lccccc}
\hline & \multicolumn{2}{c}{$\begin{array}{c}\text { Nurses } \\
(\mathrm{N}=93)\end{array}$} & & \multicolumn{2}{c}{$\begin{array}{c}\text { Postal workers } \\
(\mathrm{N}=52)\end{array}$} \\
\cline { 2 - 3 } \cline { 5 - 6 } $\begin{array}{l}\text { Deter- } \\
\text { minents }\end{array}$ & $\begin{array}{c}\text { Partial } \\
\text { regression } \\
\text { coefficient }\end{array}$ & SE & & $\begin{array}{c}\text { Partial } \\
\text { regression } \\
\text { coefficient }\end{array}$ & SE \\
\hline Severity & 0.04 & 0.03 & & 0.01 & 0.01 \\
Disability & 0.54 & $0.23^{*}$ & & 0.23 & $0.10^{*}$ \\
\hline
\end{tabular}

a Time off work was a dichotomous variable with time taken off work and no time taken off work as the two categories.

- Other variables considered but not found to be significant were age, gender, score on the General Health Questionnaire, subscale totals and discrepancies on the Work Environment Scale. Two-way interactions were also considered and not found to be significant.

c Severity and disability were continuous variables.

d Disability expressed as the number of activities affected by low-back pain (both could be performed with additional pain or could not be performed because of pain).

$* \mathrm{P}<0.05$ amined with the use of the threshold score described by Goldberg (20). GHQ scores of 5 or less are considered to be within the normal range. Examination of the proportion of cases and noncases among the two working populations with a GHQ score over 5 did not reveal any statistically significant difference between the cases and noncases (table 3). In contrast, the majority of the patients demonstrated elevated GHQ scores. The proportion of chronic low-back pain patients with GHQ scores over 5 was significantly higher than the proportion of working cases with elevated scores $\left(\mathrm{X}^{2}{ }_{(1)}=45.15, \mathrm{P}<0.001\right)$. The proportion of patients still working in some capacity with GHQ scores over 5 did not differ from the proportion of nonworking patients with elevated scores.

\section{Predictors of time off work}

Multiple logistic regression was used to explore whether the psychosocial variables or the low-back pain measures (severity and disability) were associated with time taken off work among the nurse and postal worker cases. Severity of pain was found to predict time off work for the nurses, while being disabled in a greater number of daily activities (disability) predicted time off work for the postal workers. These two variables were in fact moderately correlated (correlation coefficent $=0.5$ for both the nurses and the postal workers) and, when considered together in regression models, disability was found to be the most important predictor of time off work for both working groups (table 4). Other variables considered, but not found to be significant, were age, gender, GHQ score, and the subscale totals and discrepancies of the Work Environment Scale. Two-way interactions between these variables were also considered and found not to be significant.

\section{Predictors for disability}

Multiple regression was used to explore whether the psychological state variables or severity of pain was more associated with disability (as has already been

Table 5. Multiple regression of disability. ${ }^{\mathrm{a}} \mathrm{b}\left(\mathrm{GHQ}=\right.$ General Health Questionnaire, $\mathrm{R}^{2}=$ the multiple correlation coefficient which estimates the explained variability of each model)

\begin{tabular}{|c|c|c|c|c|c|c|}
\hline \multirow[b]{2}{*}{ Determinants } & \multicolumn{2}{|c|}{$\begin{array}{c}\text { Nurses } \\
(\mathrm{N}=104)\end{array}$} & \multicolumn{2}{|c|}{$\begin{array}{l}\text { Postal workers } \\
(N=58)\end{array}$} & \multicolumn{2}{|c|}{$\begin{array}{l}\text { Patients } \\
(\mathrm{N}=42)\end{array}$} \\
\hline & $\begin{array}{l}\text { Partial } \\
\text { regression } \\
\text { coefficient }\end{array}$ & $S E$ & $\begin{array}{l}\text { Partial } \\
\text { regression } \\
\text { coefficient }\end{array}$ & SE & $\begin{array}{l}\text { Partial } \\
\text { regression } \\
\text { coefficient }\end{array}$ & $\mathrm{SE}$ \\
\hline $\begin{array}{l}\text { Regression intercept } \\
\text { Severity } \\
\text { GHQ score } \\
\text { Severity by GHQ score } \\
\mathrm{R}^{2}\end{array}$ & $\begin{array}{c}1.79 \\
0.11^{*} \\
-0.50 \\
0.01 \\
0.53\end{array}$ & $\begin{array}{l}2.24 \\
0.05 \\
1.23 \\
0.03\end{array}$ & $\begin{aligned} & 2.47 \\
& 0.17^{* *} \\
&-0.67 \\
&-0.03 \\
& 0.52\end{aligned}$ & $\begin{array}{l}3.26 \\
0.06 \\
1.83 \\
0.03\end{array}$ & $\begin{array}{l}19.40^{\star *} \\
-0.07 \\
-8.52^{*} \\
0.09^{\star} \\
0.29\end{array}$ & $\begin{array}{l}4.11 \\
0.05 \\
3.28 \\
0.04\end{array}$ \\
\hline
\end{tabular}

a Disability expressed as the number of activities affected by low-back pain (could be performed with additional pain or could not be performed because of pain).

b The regression models for the nurses and postal workers include the interaction term to facilitate direct comparison with the model for the patients.

* $\mathrm{P}<0.05,{ }^{* *} \mathrm{P}<0.01$. 
defined) among both working populations and the chronic low-back pain patients. Two-way interactions between these variables were also considered. The results for the pain patients were markedly different from those of the two working populations, which were similar to each other (table 5). Severity of pain was an important predictor of reported disability in all three groups. However, the interaction term between psychological state and severity was significant only in the model describing patient cases. Specifically, the presence of psychological disturbance modified the relationship between severity and disability only among the patients. This finding is illustrated in figure 4 , which presents the predicted scores obtained from the regression models incorporating the interaction term (from table 5). For both groups of working low-back pain cases, the functions describing those individuals with, and those individuals without, elevated GHQ scores were completely overlapping. They therefore appear in the figure as a single function for each working group. Moreover, the functions for both the nurses and the postal workers were very similar, clearly showing a positive linear relationship between disability and the severity of pain. For the patients, in contrast, the GHQ score had an impact on the relationship between severity and disability. The function for the patients who did not have GHQ scores greater than 5 was similar to that of the working cases, whereas for those patients with elevated GHQ scores this function was essentially a flat line (ie, the reported disability tended to be at the same high level over the range of reported severity).

\section{Discussion}

The present study directly compared the experience of low-back pain and its psychosocial concomitants among sufferers drawn from a patient population with the corresponding factors among sufferers drawn from working populations. The experience of low-back pain among working cases was impressively similar, although of course less debilitating, to that reported by patients. Similar sites of pain were reported, disability occurred in a similar range of activities, and the distributions of the severity of pain overlapped.

The findings of major interest concern the differences between the working and nonworking groups regarding the involvement of psychological variables. The results confirm observations made in the literature that patient populations are in the dysfunctional range for psychological variables. See reference 3 for a review. In contrast, the low-back pain cases still at work did not demonstrate any marked psychological dysfunction. Indeed, the working cases did not differ from working noncases at all on the psychological indices.

The nature of the role of psychological factors with respect to cause and effect remains unclear. One pos-
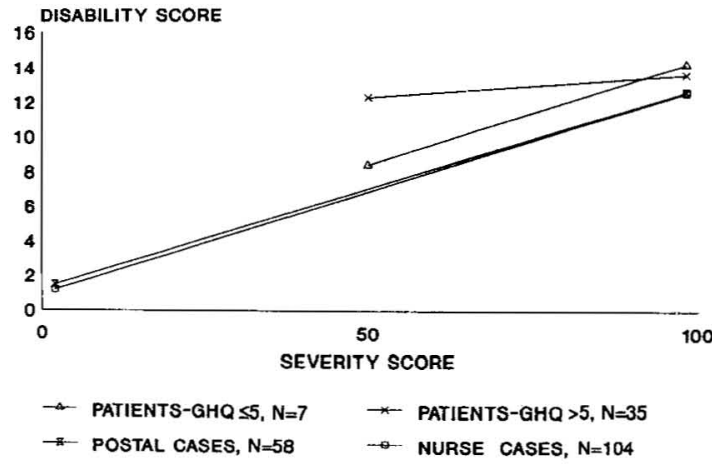

Figure 4. Disability as a function of the interaction between severity as marked on the visual analogue scale and psychological state as measured by the General Health Scale (GHQ).

sibility is that psychological distress is simply a consequence or by-product of chronic low-back pain, with no etiologic role in any aspect of the development of the disorder. That is, the differences between patients and working cases observed in this study reflects the time factor in pain experience. Patients have had pain longer and therefore have had time to develop the psychological sequelae of chronic pain. Several authors have reported that changes in psychological status appear to be associated with the persistence of back pain $(2,5)$.

Alternatively, it is possible that psychological factors may have an etiologic role in the transition from being a back pain sufferer, either chronic or acute, to being a chronic back pain patient. This transition to chronic pain patient may be a qualitatively different experience, rather than just a matter of time along a continuum from acute low-back pain to chronic lowback pain to low-back pain patient. It should be noted that the aforementioned association between the duration or persistence of symptoms and the aforementioned psychological status has typically been evaluated among sufferers drawn from patient populations. The same time-related association may not occur for sufferers drawn from working populations. Thus workers with back pain may develop a chronic history without becoming patients and psychological factors may only have a role for cases who are, or who will become, patients.

Irrespective of whether or not psychological factors have an etiologic role in the transition to chronic pain patient, it is clear that low-back pain cases still at work do not share common attributes with patient populations in terms of psychological factors. As with all of the cross-sectional studies in the literature, no information was available in this study about the patients before they became patients. This lack makes it impossible to determine whether they were individuals who had earlier had underlying psychopathology either as acute sufferers or prior to their experiencing any pain at all. 
Further evidence for the fundamental differences between low-back pain in working groups and patient groups was provided by the analysis of factors associated with taking sick leave due to back pain. When time was taken off work by working cases, it was unambiguously associated with the disability caused by low-back pain and not with any psychosocial variable, either alone or as part of an interaction term. Thus temporarily leaving work because of low-back pain, that is, taking sick leave, is not related to psychological variables. In contrast, having left work in the long term as a low-back pain patient was associated with psychological variables. It appears that taking sick leave but returning to work is a qualitatively different experience, rather than only a quantitatively different experience, to long-term withdrawal from work due to low-back pain.

When possible multivariate associations with disability were tested, psychological state was important for the chronic low-back pain patients, but not for the low-back pain cases from the two working populations. Specifically, for patients with elevated GHQ scores the level of pain did not predict the level of disability reported. In contrast, as the level of pain reported by working cases increased, the level of disability reported also increased, irrespective of the GHQ score. Most intriguingly, this linear relationship was also evident for the small proportion of patients without psychological dysfunction. This latter finding confirms reports in the literature that subgroups of patients with different personality profiles exist (24-26). Thus the transition to patient status may not always be associated with psychological risk factors.

Overall, the postal workers were more dissatisfied with their work than the nurses were. Irrespective of the level of dissatisfaction with work, however, no relationships were found with low-back pain. The cases did not differ from the noncases with respect to work satisfaction. Nor were low-back pain outcomes such as disability or taking time off work related to level of work satisfaction.

There are a number of possible sources of bias in this study. Since participation in the study was on a voluntary basis, sampling bias needs to be considered. The workplaces and patient clinic were visited at various times of the day and week, and all potential subjects present were approached as participants. As there were no refusals, biased selection of participants is unlikely to have been a problem.

The second source of bias may have arisen because of the low response rate in one of the working groups, mail sorters. The low response rate in this group probably reflects the fact that the postal delivery officers and nurses were able to be individually contacted at the workplace for follow-up, whereas the mail sorters were not available for individual follow-up. However, the similarity between the responses obtained from the mail sorters and postal delivery officers, for whom the response rate was at an acceptable level, suggests that this possible source of bias did not affect the findings.

In summary, the present study did not reveal any differences between working cases and noncases with respect to the two most promising psychosocial risk factors for low-back pain described in the literature, namely, psychological state and work dissatisfaction. These results are in sharp contrast to those reported recently by Bigos et al (19), who found that both factors predicted reporting of a back injury in a working population. In the present study, psychosocial factors were not associated either with having experienced lowback pain or with the consequences of pain among sufferers drawn from working populations. Even when sick leave was taken due to back pain, psychosocial factors were not found to be associated. However, taking sick leave due to low-back pain does not necessarily require a formal report of injury. It may be that the risk factors that determine the reporting of an injury only partially overlap with the risk factors for experiencing pain. It is also likely that those individuals who experience pain are at an earlier phase in their pain history than those who report an injury. Thus filing an injury claim may be an important qualitative difference in outcome.

This cross-sectional study has raised more questions than it has answered. The results indicate that psychological factors are more likely to be associated with being a patient with low-back pain than to be associated with being a back pain case at work and, furthermore, that psychological factors are not a prerequisite for developing low-back pain at work. The findings of others indicate that psychosocial factors are associated with back pain at work when a back injury claim has been filed (19). It may be that filing a claim for injury is an early marker for those who will eventually become chronic patients. These important differences between working groups, and between working and patient groups, only further underscore the need for an unambiguous assessment of the role of risk factors in the onset and course of low-back pain in working groups. The issues raised in this paper are currently being addressed in a prospective study of a high-risk group.

\section{Acknowledgments}

We wish to thank the management, unions, and employees of the Prince of Wales Hospital and Australia Post; Ms J Barry and Mr S Russo, occupational health and safety officers of the Prince of Wales Hospital and Australia Post, respectively; Dr D Gronow and the staff of the Sydney Pain Management Centre; and Ms N Rassack, Research Officer, National Institute of Occupational Health and Safety.

The views expressed in this article are those of the authors and do not necessarily reflect those of the National Occupational Health and Safety Commission. 


\section{References}

1. Feuerstein M, Sult S, Houle M. Environmental stressors and chronic low back pain: life events, family and work environment. Pain 1985;22:295-506.

2. Garron DC, Leavitt F. Chronic low back pain and depression. J Clin Psychol 1983;39(4):486-93.

3. Love AW, Peck CL. The MMPI and psychological factors in chronic low back pain: a review. Pain 1987; 28:1-12.

4. Rosen JC, Frymoyer JW, Clements JH. A further look at validity of the MMPI with low back pain patients. J Clin Psychol 1980;36(4):994-1000.

5. Sternbach RA, Wolf SR, Murphy RW, Akeson WH. Traits of pain patients: the low-back "loser." Psychosomatics 1973;14:226-9.

6. Åstrand NE. Medical, psychological and social factors associated with back abnormalities and self reported back pain: a cross sectional study of male employees in a Swedish pulp and paper industry. Br J Ind Med 1987; 44:327-36.

7. Åstrand NE, Isacsson SO. Back pain, back abnormalities, and competing medical, psychological and social factors as predictors of sick leave, early retirement, unemployment, labour turnover and mortality: a 22 year follow up of male employees in a Swedish pulp and paper company. Br J Ind Med 1988;45:387-95.

8. Frymoyer JW, Pope MH, Clements, JH, Wilder DG. Risk factors in low back pain. J Bone Jt Surg 1983; 65(2):213-8.

9. Nagi SZ, Riley LE, Newby LG. A social epidemiology of back pain in a general population. J Chronic Dis 1973;26:769-79.

10. Videman T, Rauhala H, Lindström K, Cedercreutz G, Kamppi M, Tola S, Troup JDH. Patient handling skill, back injuries, and back pain: an intervention study in nursing. Spine 1989;14(2):148-56.

11. Bergenudd $\mathbf{H}$, Nilsson $\mathbf{B}$. Back pain in middle age; occupational workload and psychologic factors: an epidemiologic survey. Spine 1988;13(1):58-60.

12. Magora A. Investigation of the relation between low back pain and occupation: V. psychological aspects. Scand J Rehabil Med 1973;5:191 -6.

13. Svensson HO. Low back pain in forty to forty-seven year old men: II. socio-economic factors and previous sick- ness absence. Scand J Rehabil Med 1982;14:55-60.

14. Bigos SJ, Spengler DM, Martin NA, Zeh J, Fisher L, Nachemson A. Back injuries in industry: a retrospective study: III. employee related factors. Spine 1986; $11: 252-6$

15. Linton SJ. Risk factors for neck and back pain in a working population in Sweden. Work Stress 1990;4(1): $41-9$.

16. Svensson H-O, Andersson GBJ. Low back pain in 40to 47-year-old men: work history and work environment factors. Spine 1983;8:272-6.

17. Dehlin JL, Berg S. Back symptoms and psychological perception of work: a study among nursing aides in a geriatric hospital. Scand J Rehabil Med 1977;9:61-5.

18. Skovron ML, Nordin M. Sterling RC, Mulvihill MN. Patient care and low back injury in nursing personnel: trends in ergonomics/human factors IV. Amsterdam: Elsevier, 1987:855-62.

19. Bigos SJ, Battie MC, Spengler DM, Fisher LD, Fordyce WE, Hansson TS, et al. A prospective study of work perceptions and psychosocial factors affecting the report of back injury. Spine 1991;16(1):1-6.

20. Goldberg $\mathbf{D}$. The general health questionnaire. Windsor, Berkshire: Nfer-Nelson Publishing Company, 1978.

21. Moos RH. Work environment scale. Palo Alto, CA: Consulting Psychologists Press, 1986.

22. SAS Institute Inc. Statistical analysis for personal computers, Revision 6.03. Cary, NC: SAS Institute Inc, 1987.

23. Biering-Sorenson F. A one-year prospective study of low back trouble in a general population: the prognostic value of low back history and physical measurements. Dan Med Bull 1984;31:362-75.

24. Bradley LA, Prokop CK, Margolis R, Gentry WD. Multivariate analyses of the MMPI profiles of low back pain patients. J Behav Med 1978;1(3):253-72.

25. Bradley LA, Van der Heide LH. Pain-related correlates of MMPI profile subgroups among back pain patients. Health Psychol 1984;3(2):157-74.

26. Hart RR. Chronic pain: replicated multivariate clustering of personality profiles. J Clin Psychol 1984;40(1):12933.

Received for publication: 17 January 1992 